\title{
La génesis de las bibliotecas universitarias en España
}

\author{
Genaro Luis García López \\ Olga María López Álvarez
}

Artículo recibido:

30 de junio de 2004.

Artículo aceptado:

3 de noviembre de 2004

\section{RESUMEN}

Análisis de la institución de la universidad en España en el tránsito entre el Antiguo Régimen y la sociedad liberal en el que se destacan los objetivos que los reformadores pretendían conseguir y los problemas existentes. A partir de caracterizar los centros educativos superiores se analiza la biblioteca universitaria, su desarrollo previo hasta el primer tercio del siglo XIX, su consolidación con la integración de los fondos bibliográficos de las comunidades religiosas suprimidas, su doble caracterización como biblioteca de centro educativo y pública, y sus principales problemas y su posible servicio para el desarrollo cultural y científico del país.

Palabras clave: Antiguo Régimen; Sociedad liberal; Biblioteca universitaria; Biblioteca pública; España; Siglo XIX. 
Genesis of university libraries in Spain

Genaro Luis García-López y Olga María López-Álvarez

An analysis of the university in Spain is made in its transition from the "Ancien Régime" to the liberal society, stressing the aims the reformers sought to obtain and the coexisting problems they encountered. After characterizing the higher education centers, an analysis of the university library is made: its previous development up until the first third of the XIX Century; the consolidation of its holdings after integrating the documents had by the suppressed religious communities (the Jesuits); its double character as library and public education center; and its main problems and the possible service it lent to the cultural and scientific development of the country.

Keywords: "Ancien Régime”; Liberal society; University library; Public library; Spain; XIX Century.

\section{INTRODUCCIÓN}

E ste artículo analiza los orígenes de las bibliotecas universitarias tal y como se conciben a partir de la primera mitad del siglo XIX: como un sistema bibliotecario formado por centros bibliográficos que servían tanto al conjunto de la comunidad universitaria como a la población en general (por su doble condición de bibliotecas público-provinciales y de centros educativos), pero que se pretendía que estuviesen sometidas al control gubernamental.

En primer lugar se ha considerado la biblioteca dentro del marco más amplio de las universidades, instituciones que sufrieron cambios trascendentales durante la primera mitad del siglo XIX y pasaron de ser organismos anquilosados y dominados por las enseñanzas tradicionales — con un marcado carácter tomista y con escasa innovación- a nuevas entidades que se pretendía que fueran adecuadas a la nueva realidad social imperante con la revolución liberal, estuvieran al servicio de una nueva estructura social e implicaran planteamientos educativos y científicos diferentes.

Las mejoras en la universidad, incubadas en las reformas ilustradas de Carlos III, requerían bibliotecas universitarias claramente definidas, bien dotadas y al servicio de la docencia y la investigación. Como punto de referencia, los 
liberales miraban más allá de las fronteras españolas. Frente a universidades ancladas en la tradición y poco abiertas a los cambios existentes (ya a las puertas de la revolución liberal) y anquilosadas aún más durante el reinado de Fernando VII, los liberales buscaron la comparación con Francia o el Reino Unido como modelos de universidad y de biblioteca para España.

Este trabajo estudia también hasta qué punto se consiguió la modernización (es decir, la europeización). Pero antes es necesario perfilar las peculiaridades de las bibliotecas universitarias españolas, su proceso de formación y los problemas a que se vieron sometidas durante todo el periodo analizado.

Pero además nos interesa saber en qué medida las bibliotecas podían coadyuvar al desarrollo de la ciencia en las universidades españolas o si, por el contrario, eran estructuras anticuadas y que estaban al margen de la investigación científica. En última instancia queríamos saber si al menos las bibliotecas servían para proveer los libros y revistas que circulaban por Europa y en los que se difundían los conocimientos científicos que se estaban desarrollando en aquellos años:

¿Cómo eran aquellas bibliotecas universitarias?

¿De qué recursos podían disponer?

¿Cuál era el grado de actualización de sus fondos?

A todas estas preguntas pretendemos responder en este estudio. Cronológicamente hemos considerado un periodo más o menos amplio, pero que se centra fundamentalmente en los dos primeros tercios del siglo XIX, pues fue en esos años cuando se formaron las bibliotecas universitarias y se consolidaron los elementos que las habrían de definir durante el resto del siglo. Como otro más de los departamentos que componen el organigrama de cada una de las universidades, las bibliotecas de la España de la primera mitad del siglo XIX se van a ver profundamente afectadas por las vicisitudes por las que fueron pasando las propias universidades.

En cuanto a la investigación, se destaca la falta de estudios acerca de la historia de la biblioteca universitaria en España, pues aunque existen análisis concretos sobre algunas bibliotecas de universidades determinadas, ${ }^{1}$ no así una investigación de tipo general sobre todas ellas en conjunto. La constatación que realizaban las bibliotecarias Pilar Faus Sevilla y Francisca Aleixandre Tena, en los años setenta del siglo XX, sobre el escaso interés por los aspectos históricos de las bibliotecas universitarias en España y el retraso de estas investigaciones en comparación con otros países europeos, lamentablemente sigue siendo una realidad.

1 Especialmente los trabajos de Ramón Rodríguez Álvarez sobre la Biblioteca de Oviedo y de Aurora Miguel Alonso sobre la Biblioteca de los Reales Estudios de San Isidro. 
Durante el Antiguo Régimen la universidad impartía las disciplinas características de aquella sociedad. Así, las facultades existentes fueron las requeridas para la formación de los profesionales que eran demandados en aquella época: en primer lugar teología, como manifestación del tremendo poder de la Iglesia; en segundo lugar, leyes y cánones, donde se formaba la burocracia al servicio de las instituciones del poder político y religioso; y, finalmente, medicina (única disciplina científica que se impartía en las universidades de la época).

Aunque el reformismo ilustrado del siglo XVIII en España intentó la difusión de nuevos saberes durante el primer tercio del siglo XIX, el sistema universitario (y el educativo en general) seguía siendo bastante arcaico y anquilosado. Si se quería reformar el sistema educativo en un sentido modernizador (o sea, más próximo al de los países europeos más avanzados) se debían potenciar las ciencias naturales, la física, la química, la matemática y otras ciencias, con el fin de conseguir el desarrollo, incrementar la riqueza y avanzar en el fomento económico y social.

De haberse conseguido esas reformas, el sistema educativo, y dentro de éste la universidad, se habría convertido en un motor de cambio que hubiera logrado la realización plena de todas las facultades del país y conseguido así una explotación de las fuentes de riqueza de la nación sin las cortapisas de los estamentos, la propiedad vinculada y los antiguos gremios. Junto a esto, la universidad habría permitido también el cultivo de los saberes que, desde el siglo XVIII, venían desarrollándose al margen de las estructuras educativas.

Para alcanzar los objetivos de los reformadores (ilustrados primero, liberales después) se necesitaba previamente una reforma interna de la propia institución universitaria ${ }^{2}$ y, sobre todo, se precisaba que el Estado hiciése un cambio (que la universidad por sí sola no estaba dispuesta a llevar a cabo por el entramado de intereses corporativos existentes) y sometiera la universidad a un proceso de centralización (dependencia del Ministerio que ostentase las competencias de instrucción pública, el nombramiento de rectores, el control financiero, etcétera). ${ }^{3}$

Junto a la centralización, los políticos liberales utilizaron la racionalización y la uniformidad; es decir, un único modelo universitario para todos los casos. La racionalidad supuso la supresión de las universidades menores

2 Las universidades de aquellos años se centraban en la repetición de saberes ancestrales ya superados y estaban controladas en gran parte por la Iglesia y al margen de las autoridades civiles. Además, la independencia universitaria era sobre todo una excusa para evitar la injerencia del poder civil y su posible modernización. poránea, Madrid, Instituto de Estudios Administrativos, 1972, pp. 87 y ss. 
(generalmente trasladadas a otras poblaciones o convertidas en institutos de enseñanza secundaria) y la creación de otras en ciudades importantes que no las tenían (como Madrid y Barcelona).

Al albur de los tres criterios señalados se reorganizó el mapa universitario y se crearon diez distritos universitarios con sus respectivas universidades: Sevilla, Granada, Madrid, Valencia, Salamanca, Valladolid, Zaragoza, Barcelona, Oviedo y Santiago.

Con ese sistema racional y uniforme se pretendió conformar un mapa universitario regido por criterios apartados de las peculiaridades históricas y en los que primaba un planteamiento abstracto, que buscaba crear una geografía universitaria diseñada desde el centro político. Con ello se pretendía superar las concepciones pedagógicas arcaicas (el tomismo) y difundir conocimientos más útiles para las nuevas élites ilustradas.

Pero esto requería además de un cambio en los métodos pedagógicos, en las enseñanzas impartidas y en las propias estructuras orgánicas de las instituciones. Todo lo cual repercutió en el desarrollo de la biblioteca como un centro clave tanto de la instrucción como de la investigación de nivel superior.

Sin embargo se partía de una situación realmente complicada, pues la universidad del primer tercio del siglo XIX era una institución que estaba casi al margen de la ciencia y de todo progreso de los saberes. Así, Peset, Garza y Pérez Garzón afirman que, durante ese periodo, España

"careció de producción científica organizada. En otros términos, las universidades no ofrecieron una enseñanza al día de las matemáticas, física, química o ciencias naturales y mucho menos llegaron a constituir centros de producción científica". ${ }^{4}$

Con el plan de estudios de 1845 se consolidó la universidad liberal y dio comienzo una etapa de mayor estabilidad y modernización. Así, los establecimientos educativos se fueron dotando (lenta pero progresivamente, aunque siempre con pocos recursos) de ciertos medios necesarios para la docencia y la investigación.

La culminación del proceso de institucionalización de la enseñanza se llevó a cabo siendo Ministro de Fomento Claudio Moyano, al aprobar las Cortes la ley de bases para desarrollar un plan de estudios que integrase todos los niveles educativos, que era al mismo tiempo una ley recopiladora de la dispersa normativa anterior. Además, se creó la facultad de ciencias, con lo que se consiguió la consolidación de esta disciplina en el sistema educativo.

4 J.L. Peset, S. Garma y J.S. Pérez Garzón, Ciencias y enseñanza en la revolución burguesa, Madrid, Siglo Veintiuno, 1978, p. 38. 
Las universidades tuvieron necesidad de contar con libros desde sus orígenes para desempeñar sus funciones docentes; sin embargo, sus colecciones solían ser poco importantes y tenían escasa difusión. Así, en el siglo XVI, en la biblioteca de la Universidad de Santiago, los libros estaban amontonados en un rincón del claustro, al cuidado de un bedel y encadenados. ${ }^{5}$ En el siglo XVIII la biblioteca mejoró notablemente, se habilitó un nuevo local que se dotó de mobiliario y se llevó a cabo una política sistemática de compra de libros.

Tras la expulsión de los jesuitas la biblioteca incrementó considerablemente sus fondos, pues los libros de la Compañía de Jesús pasaron, en gran parte, a formar parte de la biblioteca universitaria. Debido a ello se nombró un bibliotecario para que se encargase específicamente de la biblioteca, se elaboró un reglamento y se realizaron inventarios de sus fondos. ${ }^{6}$

Las constituciones de la biblioteca de Santiago de Compostela del 26 de septiembre de 1794 presentaban una biblioteca perfectamente definida, ${ }^{7}$ con un bibliotecario mayor, dos menores y un portero, y establecía los sueldos de éstos, los procedimientos para su nombramiento y sus tareas; los horarios de apertura de la biblioteca; la obligatoriedad de elaborar índices de impresos (uno alfabético de autores y otro de materias con suplementos para las nuevas adquisiciones), manuscritos (idem) y libros prohibidos; la colocación de los libros y su estricto control por parte de los bibliotecarios; la adquisición de obras en las almonedas y la formación de una junta para cuidar de la biblioteca. En cuanto al uso de los libros, es interesante destacar que se seguía un criterio preferentemente conservador. ${ }^{8}$

El modelo seguido por la biblioteca de la Universidad de Santiago fue similar al de las demás universidades: hasta el siglo XVIII la biblioteca fue un espacio poco definido que tenía escasos libros, poca variedad bibliográfica y que hacía una escasa utilización del fondo (en consonancia con el modelo universitario imperante). Pero en ese mismo siglo aumenta el fondo, se destinan espacios mejor acondicionados para albergar la biblioteca, se regula el

5 Mercedes Alsina Gómez-Ulla, "Algunas noticias sobre don Francisco del Valle Inclán, primer bibliotecario de la Universidad de Santiago", en Homenaxe a Daría Vilariño, Santiago de Compostela, Universidade, Servicio de Publicacións e Intercambio Científico, 1993, pp. 243-251, p. 245.

6 Mercedes Alsina Gómez-Ulla, "Algunas ...", pp. 246-248.

7 Anteriormente se solía llamar librería y, en general, en la época, se diferenciaba entre librería (pocos libros y tal vez sin orden y sin catálogo, y posiblemente sin personal específico) y biblioteca (mayor entidad, con bibliotecario(s), catálogos, un edificio adecuado, mobiliario y otros enseres).

8 Casimiro Torres Rodríguez, "Las constituciones de la biblioteca universitaria de Santiago y su primer catálogo en el siglo XVIII", en Cuadernos de estudios gallegos, XX, núm. 60 (1965), pp. 109-119. 
uso de ella, comienzan a aparecer bibliotecarios para hacerse cargo específicamente de la atención de la biblioteca y éstas se enriquecen con los libros de la Compañía de Jesús tras su supresión y la expulsión de los religiosos.

Así todo existían diferencias entre unos casos y otros. Por ejemplo, tras la expulsión de los jesuitas, la Universidad de Granada fue trasladada al colegio de San Pablo y su biblioteca incorporada a la Universidad. Según los inventarios de la época el colegio tenía un fondo de 29.483 volúmenes impresos, además de los manuscritos. Por tanto, la pequeña librería universitaria se vio incrementada considerablemente con los fondos jesuíticos, y ello hizo necesario el nombramiento de un bibliotecario (Juan Gil Palomino) en 1780.

Además existían universidades con una gran tradición en ciudades de cierta importancia ${ }^{10}$ y otras que se encontraban en peores condiciones. Este último era, por ejemplo, el caso de Cervera, una pequeña población donde Felipe V mandó trasladar el centro universitario. Desde 1750 la Universidad contaba con unos estatutos que indicaban cómo debía ser la biblioteca, los horarios de apertura y quién se debía ocupar de ella. Según daba cuenta el cancelario Ramón Llàtzer de Dou en un informe del 9 de febrero de 1807, la situación de la biblioteca universitaria era la siguiente:

[...] esta Universidad, con tantos privilegios y con un edificio que, por todas partes, ostenta la magnanimidad de su fundador, no tiene bibliotheca chica, ni grande, en donde puedan los pobres estudiantes instruirse con libros de su profesion [...] quando la expulsión de los Jesuitas se nos aplicaron los que havia en el colegio de dichos regulares de esta Ciudad, que era uno de los más pobres de nuestra Provincia. A esto que es bien poco, viene a reducirse todo lo que tenemos en quanto a libros.

Lo peor es que, lo poco que tenemos, de nada y a nadie sirve por falta de bibliothecario. Los estatutos encargan la obligacion de cerrar y abrir la bibliotheca al bedel menor. Como por otra parte no hay dotación, ni disposición, para que otro esté a todas horas en la bibliotheca, ha querido entenderse, que el bedel menor era, o es el bibliothecario; más sobre ser un bedel persona poco o nada oportuna para bibliotecario, tiene nuestro bedel menor otras obligaciones incompatibles. Las resultas de esta inteligencia han sido que de nada sirven los pocos libros que tenemos. Lo cierto es que en treinta y un años que llevo de Cervera entre estudio, Cátedra y Cancelario, jamás he visto pública y corriente nuestra bibliotheca, y que cuando estaba de catedrático de prima de leyes, no podia sino con mucha dificultad

9 Cristina Peregrín Pardo, "La biblioteca universitaria de Granada. Ayer y hoy", en Boletín de la Asociación Andaluza de Bibliotecarios, vol. 1, núm. 0 (junio 1984), pp. 8-12.

10 Con edificios notables como el de la universidad de Salamanca, con un amplio salón abovedado, reformado a mediados del siglo XVIII. María Fe Díaz Tordesillas, La biblioteca universitaria de Salamanca y sus verdaderos artifices, Salamanca, Publicaciones de la Asociación de Antiguos Alumnos y Amigos de la Universidad de Salamanca, 1969. 
conseguir que se me abriese en los casos en que por algun motivo particular me convenia. ${ }^{11}$

La Universidad de Oviedo se vio favorecida por el legado del brigadier asturiano Lorenzo Solís, lo que permitió que se organizara una biblioteca a partir de los libros que existían en la librería desde comienzos del siglo XVII. El legado de Solís aportó recursos para la compra de libros y para pagar a un bibliotecario que atendiese la colección. Por una real provisión del 16 de febrero de 1765, el Supremo Consejo ordenó que se crease la biblioteca pública que, aunque se integraba dentro de la Universidad, estaba dotada de una cierta independencia (por ejemplo, sus bienes eran administrados por personas no pertenecientes a la Universidad y el bibliotecario no dependía directamente del rector, y además estaba regida por un patronato). ${ }^{12}$

A comienzos del siglo XIX las bibliotecas universitarias habían alcanzado un elevado grado de madurez y tenían entidad propia en las universidades españolas. El plan de estudios de 1807, que era específico para Salamanca pero que serviría de modelo para las demás universidades, indicaba el número de bibliotecarios que debían tener las bibliotecas de las universidades, las fechas y horarios de apertura y señalaba la importancia de éstas dentro de la institución universitaria y de la cultura en general; así, rezaba que:

"la Biblioteca pública será uno de los establecimientos que más deban procurarse y mejorarse sucesivamente, haciéndole cierta asignacion para su servicio y compra de libros". 13

El primer tercio del siglo XIX supuso un considerable paso atrás respecto a los avances conseguidos en el siglo anterior. A pesar de los problemas que podían tener, a finales del siglo XVIII las grandes universidades contaban con bibliotecas de una cierta importancia, con bibliotecarios que las atendían, con locales específicos y en general bien acondicionados para la colocación del fondo, y con colecciones más o menos ricas que, tras la expulsión de los jesuitas, solían alcanzar varios miles (en algunos casos varias decenas de miles) de volúmenes.

Tras la crisis del primer tercio del siglo XIX hubo que empezar casi desde cero. La Guerra de la Independencia fue nefasta para algunas ciudades como Zaragoza y Valencia, y además, el periodo post-bélico no fue especialmente benigno para las bibliotecas. La recuperación de los fondos bibliográficos

11 La Biblioteca de la Universitat de Barcelona, Barcelona, Universitat de Barcelona, Publicacions, 1994, pp. 18-19.

12 Ramón Rodríguez Álvarez, La Biblioteca de la Universidad de Oviedo 1765-1934, Oviedo, Universidad de Oviedo, 1993, p. 31 y ss. 
fue lenta porque las universidades estaban en una situación financiera poco halagüeña y la guerra había sido devastadora.

Pero más negativo aún fue el intento de controlar "las lecturas" por parte de los políticos absolutistas fernandinos. Las bibliotecas eran consideradas como incluso más peligrosas que el profesorado, porque potencialmente, en ellas se podrían encontrar libros que difundiesen las ideas ilustradas o revolucionarias. Por tanto no sólo no existió un deseo de recuperar las bibliotecas universitarias, sino que se intentó impedir la circulación de libros por el peligro de que se difundieran las teorías no absolutistas.

En el caso de la Universidad de Oviedo su biblioteca fue sometida a una visita regia en 1815 y 1816 para controlar cualquier peligro reformista. Según los visitadores el problema no residía tanto en los profesores, sino en la libertad para introducir libros extranjeros y en la facilidad con que se había podido acceder en los años anteriores a libros prohibidos, ubicados en la biblioteca:

"[...] la introducción de libros extrangeros en el reyno no hay duda que contribuyó mucho a que por todo él se difundiesen ideas perjudiciales en sumo grado", y añaden "el origen de las máximas antirreligiosas y antipolíticas que se han introducido es atribuido... justamente a los libros franceses y a los periódicos españoles de la época de las Cortes."

Uno de los visitadores, Ramón de la Cuadra, indicaba:

"aun tengo entendido que antes de la invasión, la Biblioteca de esta Universidad, por no guardarse con reserva las obras de autores anticatólicos, fue donde nuestros jóbenes se contagiaron con el veneno de las opiniones exaltadas". ${ }^{14}$

Preocupaba especialmente que la biblioteca pudiese ofrecer sus fondos a todo el mundo sin tener un control previo de los libros no autorizados. En esas condiciones las bibliotecas, consideradas como lugares peligrosos para el mantenimiento del orden político imperante, difícilmente podían prosperar.

\section{LA REVOLUCIÓN LIBERAL ANTE LAS BIBLIOTECAS UNIVERSITARIAS}

A la muerte de Fernando VII, las bibliotecas universitarias se encontraban -como ocurría con las universidades en general- en una situación lamentable.

14 Ramón Rodríguez Álvarez, La Biblioteca ..., pp. 74-79. Según el autor, los libros de texto fueron los que sufrieron la mayor "persecución" (mayor que la de los profesores que eran mayoritariamente afines al absolutismo) por parte de los visitadores, quienes llegando a suprimir libros que estaban incluidos en los planes de estudio de Carlos III. 
A pesar del florecimiento obtenido durante el siglo XVIII, cuando las universidades habían ido organizando bibliotecas y dotándolas de una cierta entidad, en algunos casos con personal para su atención, con edificios propios y un número considerable de libros, la Guerra de la Independencia las hundió de manera ominosa.

Posteriormente, la Primera Guerra Carlista (1833-1840) empeoró aún más la situación. Sin embargo durante este periodo tuvo lugar un elemento esencial para entender el posterior desarrollo bibliotecario español: la supresión de las comunidades de religiosos y la nacionalización de sus bienes.

Durante la regencia de María Cristina de Borbón se inició un proceso que fue irreversible y de largo alcance. La supresión de las comunidades religiosas comenzó en julio de 1835 y en muchos casos (especialmente en la zona levantina y andaluza) los conventos fueron suprimidos por revueltas callejeras y algunos fueron incluso saqueados. Desde el 25 de julio el Gobierno fue promulgando normativas para suprimir las comunidades religiosas, al principio con ciertas restricciones y posteriormente con una amplitud general. Hacia 1837 todos los conventos habían sido teóricamente suprimidos y cerrados, y los religiosos exclaustrados. ${ }^{15}$

Las propiedades de los religiosos fueron nacionalizadas para ser posteriormente vendidas, como fue el caso de las fincas rústicas y urbanas. Sin embargo aquellos bienes que tenían un valor artístico, arquitectónico, histórico o literario fueron conservados por considerar que primaba, sobre su valor económico, otro de rango superior, su valor cultural.

Desde julio de 1835 la Administración comenzó a promulgar normas tendientes a la conservación de dichos bienes y a su nacionalización efectiva. ${ }^{16}$ Sin embargo, el proceso nacionalizador fue lento y problemático, pues, aunque los bienes habían sido declarados estatales, lo cierto es que la nacionalización real requería la toma de posesión de los mismos, su traslado desde los edificios religiosos a edificios de la Administración, la realización de inventarios y su ubicación definitiva en lugares adecuados. ${ }^{17}$

Entre los bienes culturales nacionalizados se encontraban las bibliotecas de los conventos y monasterios suprimidos. En aquella época las comunidades religiosas eran las instituciones depositarias de la mayor riqueza bibliográfica

15 Manuel Revuelta González, La exclaustración (1833-1840), Madrid, Biblioteca de Autores Cristianos, 1976.

16 Para un análisis más detallado de la legislación nacionalizadora de los bienes culturales de las comunidades suprimidas, especialmente en materia de bibliotecas, véase: Genaro Luis García López, "El origen de la política bibliotecaria en España: la legislación de bibliotecas públicas durante la revolución liberal (1835-1842)", en Primer Congreso Iberoamericano de Derecho de la Cultura, 29 de noviembre a 2 de diciembre de 1999, Madrid, en prensa.

17 Para comprender el proceso de nacionalización de los bienes culturales y en general de las órdenes regulares véase: Josefina Bello, Frailes, intendentes y políticos: los bienes nacionales 1835-1850, Madrid, Taurus, 1997. 
del país, tanto en número de volúmenes como en el valor de ellos, pues habían ido conservando en sus bibliotecas conocimientos desde los inicios de la cristiandad.

Como era imposible que la Administración pudiese recoger la gran cantidad de libros existentes con sus propios recursos, tuvo que delegar la tarea en otras instituciones que no formaban parte del propio organigrama público. Así, se crearon comisiones especiales para recoger los objetos y para que fueran trasladados a lugares seguros y se solicitó la colaboración de instituciones educativas y culturales tanto para elaborar los inventarios y trasladar los libros, como para que éstos fueran utilizados para crear centros de lectura.

De esta manera los centros educativos superiores cumplieron un papel de trascendental importancia, pues fueron los encargados de recoger y trasladar los libros desde los edificios de los conventos y monasterios abandonados hasta sus propios edificios. Fue así como la inmensa riqueza bibliográfica de las comunidades religiosas fue a parar a las universidades, en principio como una cesión temporal por parte del Estado, pero a la larga como una donación definitiva. $^{18}$

Por Real Orden del 22 de septiembre de 1838 se otorgaron los libros nacionalizados a las universidades y se convirtió a sus bibliotecas en públicasprovinciales. Dicha orden disponía que en las provincias donde existiese universidad se encargase ella misma de recoger los libros y ofrecerlos al público (tanto a la comunidad universitaria como a cualquier lector no integrante de la misma). ${ }^{19}$

\section{LA DOBLE CARACTERIZACIÓN DE LAS BIBLIOTECAS UNIVERSITARIAS}

De esta manera a partir de 1838 las universidades comenzaron a hacerse cargo de una gran cantidad de libros, con lo que sus bibliotecas adquirieron la consideración de universitarias y públicas-provinciales, a excepción de la madrileña (ya que los libros fueron recogidos por la Biblioteca Nacional). Así, las bibliotecas tenían que servir a la comunidad docente, tanto al profesorado como al alumnado en sus tareas educativas y, por su consideración de públicas, obtenían financiación provincial, estaban abiertas al público general y recibían el depósito de las obras editadas en la provincia.

18 Para analizar el proceso de nacionalización de las bibliotecas conventuales, el papel de las universidades y el surgimiento de las bibliotecas públicas y de centros de enseñanza media y superior en España véase: Genaro Luis García López, Los orígenes del sistema español de bibliotecas públicas: La política bibliotecaria durante la revolución liberal (1835-1843), tesis doctoral defendida el 6 de noviembre de 2002 en la Facultad de Humanidades, Comunicación y Documentación de la Universidad Carlos III de Madrid.

19 Archivo de la Real Academia de Bellas Artes de San Fernando (ARABASF), leg. 55-2/2. 
Sin embargo, difícilmente podían realizar la función docente, pues ni los medios económicos, ni humanos con los que contaban les permitían desarrollar una labor efectiva; a lo que había que añadir la escasa preocupación por la investigación científica y humanística de calidad que existía en las universidades españolas.

En cuanto a la función desempeñada por la biblioteca pública hay que tener en cuenta varias limitaciones. En primer lugar, el depósito legal no era efectivo (en ninguna provincia se cumplían las disposiciones normativas que obligaban a que los editores depositasen ejemplares de lo que publicaban). En segundo lugar, la financiación provincial pagaba únicamente la mitad de los gastos de personal (y de la parte restante se ocupaba el Ministerio competente en instrucción pública).

En lo referente al público potencial de las bibliotecas hemos de recordar los altísimos índices de analfabetismo de la España del momento. A mediados del siglo XIX las tasas de analfabetismo de muchas provincias superaban el 75\% (Orense 89\%, Almería 88\%, Castellón 87\%, Canarias 87\%). En los casos que contaban con tasas más bajas, en casi ningún lugar eran inferiores al 50\%, por ejemplo: 46\% Álava, 54\% Madrid, 55\% Cantabria y 57\% Palencia. ${ }^{20}$ De estas cifras hemos de deducir un escaso interés por acceder a las bibliotecas universitarias y provinciales.

Además hemos de tener en cuenta otras dos limitaciones para que el público general accediera a las bibliotecas provinciales: los horarios y los fondos. En cuanto al primer aspecto, las bibliotecas solían estar abiertas exclusivamente en determinadas horas del día y éstas generalmente coincidían con los horarios de trabajo.

En segundo lugar hemos de reseñar que las bibliotecas universitarias estaban formadas por libros académicos y de divulgación científica que servían a la comunidad universitaria; sin embargo, debido a la escasez de recursos económicos y la escasa modernización de las universidades españolas, el grado de obsolescencia del fondo era bastante elevado. Las obras editadas en los países europeos llegaban con cierto retraso y no eran demasiado abundantes. ${ }^{21}$

En cuanto al número de volúmenes existentes, el dato más relevante era que la mayor parte de las obras que contenían las bibliotecas universitarias y públicas procedían de las comunidades religiosas. Y además los fondos de las bibliotecas conventuales y monacales eran poco adecuados para las bibliotecas de centros educativos del segundo tercio del siglo XIX, en una etapa de

20 José María Hernández Díaz, "Alfabetización y sociedad en la revolución liberal española", en: A. Escolano (dir.), Leer y escribir en España: doscientos años de alfabetización, Madrid, Salamanca, Fundación Germán Sánchez Ruipérez, Pirámide, 1992, pp. 69-89, pp. 72-73.

21 Aunque eso no suponía que no llegasen libros editados en otros países, especialmente de Francia, ni que la universidad española estuviese tan cerrada a la influencia europea como lo había estado durante la etapa absolutista previa. 
modernización (lenta pero evidente), de secularización (con altibajos, pero irreversible) y de implantación del capitalismo y de la sociedad de clases.

Adicionalmente los libros nacionalizados a las comunidades religiosas se caracterizaban fundamentalmente por lo siguiente:

- En cuanto a su idioma, cerca de la mitad estaban escritos en latín (con otro porcentaje importante en castellano y después otros idiomas en número minoritario, como el francés).

- En cuanto a las fechas de publicación, la inmensa mayoría eran anteriores al 1800 .

- En cuanto a las materias, la mayoría abordaban temas religiosos en sus distintas vertientes, como derecho canónico, teología, moral, sermones, libros de coro y de rezo, ejemplares de la Biblia, etcétera.

Por tanto dichos fondos servían básicamente para cursar carreras de teología o de derecho canónico o para hacer investigaciones históricas y filológicas sobre la Iglesia y la cultura sacra. Veamos algunos ejemplos que detallen estas cuestiones.

Entre junio de 1836 y febrero de 1837, los comisionados José Uría Ferrero y Pedro González Valdés elaboraron un inventario de la biblioteca del convento asturiano de San Juan de Corias, y el resultado fue que de los 1.706 títulos incluidos en el convento, únicamente cinco obras habían sido publicadas con posterioridad a 1800 ; es decir, un insignificante 0.29 por ciento. $^{22}$

Si consideramos otra biblioteca asturiana, la del convento de San Salvador de Cornellana, observamos que 11 de sus obras eran de sagrada escritura, siete de santos padres, tres de concilios, siete de teología escolástica, 18 de teología moral, 61 de mística y obras predicables y 16 de cánones. De obras no religiosas únicamente contaba con nueve de historia profana, dos de derecho, cinco de medicina, 10 de literatura y 10 de filosofía. Consiguientemente, únicamente el $23.6 \%$ eran obras no estrictamente religiosas, un porcentaje que en otras bibliotecas religiosas podía ser incluso inferior. ${ }^{23}$

Tomemos ahora en consideración el monasterio de las Avellanas de Lérida, de donde la comisión científica y artística de la provincia había recogido 831 volúmenes a mediados de 1842. 474 estaban en latín (57.03\%), 259 en castellano (31.16\%), 82 en italiano $(9.86 \%)$ y 16 en francés $(1.92 \%) .{ }^{24}$ Aunque los porcentajes variaban de unos sitios a otros, lo cierto era que en la mayoría de los casos más de la mitad de los libros estaban en latín y superaban frecuentemente a los que estaban en español, con algunas pequeñas

22 ARABASF, leg. 50-2/2, Objetos procedentes de conventos suprimidos.

23 ARABASF, leg. 50-2/2, Objetos procedentes de conventos suprimidos.

24 ARABASF, leg. 49-2/2, Museo-Biblioteca. 
cantidades de volúmenes en otras lenguas europeas (principalmente francés, algunas veces italiano, inglés, alemán o portugués) o antiguas (como griego o hebreo).

\section{Conclusiones}

Hemos analizado aquí la institución universitaria y su proceso de modernización en los siglos XVIII y XIX como manifestación de los impulsos renovadores de ilustrados y liberales.

Las bibliotecas universitarias que habían experimentado un gran avance en el siglo XVIII incrementando sus fondos y siendo dotadas de edificios, así como de medios económicos y humanos más adecuados, experimentaron un considerable retroceso durante el primer tercio del siglo XIX.

En el periodo de establecimiento del régimen liberal (que coincide con la guerra contra el carlismo desarrollada entre 1833 y 1840) se produjo la consolidación de las bibliotecas universitarias con una doble caracterización —bibliotecas públicas provinciales y bibliotecas de centros educativos- y las universidades se hicieron cargo de los bienes obtenidos de la desamortización de las comunidades religiosas.

Aunque el anticuado fondo del que tuvieron que hacerse cargo las universidades si por un lado incrementó notablemente sus colecciones, por otro las cargó de obras antiguas y de temática mayoritariamente religiosa.

Sin embargo peor todavía que la existencia de tales libros fue que la mayor parte de los recursos — tanto humanos como económicos- que se destinaron a las bibliotecas universitarias desde mediados del siglo XIX, se empleó para llevar a cabo los procesos técnicos (inventarización, catalogación, clasificación, ordenación, etcétera) de los fondos de las comunidades religiosas. Aunque las estadísticas de las bibliotecas ofrecieran datos más o menos cuantiosos sobre el número de volúmenes que albe'rgaban, lo cierto es que aquel fondo bibliográfico, además de ser poco útil para la investigación científica, sirvió para distraer los escasos recursos que pudiesen haberse orientado hacia la compra de libros más actuales y la modernización de las prácticas bibliotecarias.

De esta manera, al mismo tiempo que se desarrollaban las bibliotecas universitarias, que incrementaban sus volúmenes, que contrataban a más personal, que recibían asignaciones presupuestarias regulares cada año, que se organizaban como un departamento de la universidad, que obtenían entidad propia, que se modernizaban y que adquirían una consideración importante como elementos de primer orden para la investigación científica al servicio de universidades renovadas y que las autoridades querían modernizar; 
tenían que destinar sus recursos para atender unos fondos antiguos de un gran valor bibliográfico, e incluso histórico y literario, pero de muy poca utilidad para las investigaciones científicas; libros que eran el legado del pasado y que se podían considerar incluso como un lastre para la modernización y la innovación.

Así las bibliotecas universitarias acabarían convirtiéndose en lo que el eminente bibliotecario catalán Rubió i Balaguer denunciaba en 1918 refiriéndose a la biblioteca de la universidad de Barcelona: "la Biblioteca Universitària viu en la Universitat, però no viu amb la Universitat [la Biblioteca Universitaria vive en la Universidad, pero no vive con la Universidad]"; 25 es decir se ha convertido en una institución segregada de la vida universitaria, en tanto que no respondía a las necesidades de los miembros de la comunidad docente.

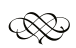

\section{BiBLIOGRAFÍA}

Alsina Gómez-Ulla, Mercedes, "Algunas noticias sobre don Francisco del Valle Inclán, primer bibliotecario de la Universidad de Santiago", en Homenaxe a Daría Vilariño, Santiago de Compostela, Universidade, Servicio de Publicacións e Intercambio Científico, 1993, pp. 243-251.

Álvarez de Morales, Antonio, Génesis de la universidad española contemporánea, Madrid, Instituto de Estudios Administrativos, 1972.

Bello, Josefina, Frailes, intendentes y políticos: los bienes nacionales 1835-1850, Madrid, Taurus, 1997.

La BIBLIOTECA de la Universitat de Barcelona, Barcelona, Universitat de Barcelona, Publicacions, 1994.

Díaz Tordesillas, María Fe, La biblioteca universitaria de Salamanca y sus verdaderos artífices, Salamanca, Publicaciones de la Asociación de Antiguos Alumnos y Amigos de la Universidad de Salamanca, 1969.

Faus Sevilla, Pilar y Aleixandre Tena, Francisca, "Bibliotecas universitarias. Su problemática actual", en Boletín de la Asociación Nacional de Bibliotecarios, Archiveros y Arqueólogos, XXVI : núm. 1-2 (enero-junio 1976), pp. 23-30.

García López, Genaro Luis, "El origen de la política bibliotecaria en España: la legislación de bibliotecas públicas durante la revolución liberal (1835-1842)", en Primer Congreso Iberoamericano de Derecho de la Cultura, 29 de noviembre-2 de diciembre de 1999, Madrid, en prensa.

25 Jordi Rubió i Balaguer, "Organització de la biblioteca de la universitat", en Sobre biblioteques i biblioteconomia, Barcelona, Departament de Cultura de la Generalitat de Catalunya, Publications de l'Abadia de Montserrat, 1995, p. 160. 
García López, Genaro Luis, Los orígenes del sistema español de bibliotecas públicas: La política bibliotecaria durante la revolución liberal (1835-1843), tesis doctoral defendida el 6 de noviembre de 2002 en la Facultad de Humanidades, Comunicación y Documentación de la Universidad Carlos III de Madrid.

Hernández Díaz, José María, "Alfabetización y sociedad en la revolución liberal española", en A. Escolano (dir.), Leer y escribir en España: doscientos años de alfabetización, Madrid, Salamanca, Fundación Germán Sánchez Ruipérez, Pirámide, 1992, pp. 69-89.

Miguel Alonso, Aurora, "Del Plan Pidal a la Ley Moyano: Consolidación de la Biblioteca de la Universidad Central", en Estudios Históricos: Homenaje a los profesores José María Jover y Vicente Palacio Atard, Madrid, Departamento de Historia Contemporánea, Facultad de Geografía e Historia, Universidad Complutense, 1990, pp. 681-701.

Miguel Alonso, Aurora. "La biblioteca de los Reales estudios de San Isidro", en Villa de Madrid, vol. XV : núm. 91 (1987), pp. 45-62.

Miguel Alonso, Aurora, La biblioteca de los Reales Estudios de San Isidro, Madrid, Editorial de la Universidad Complutense, 1992.

Peregrín Pardo, Cristina, "La biblioteca universitaria de Granada. Ayer y hoy", en Boletín de la Asociación Andaluza de Bibliotecarios, vol. 1, núm. 0 (junio 1984), pp. 8-12.

Peset, J.L., Garma, S. y Pérez Garzón, J.S., Ciencias y enseñanza en la revolución burguesa, Madrid, Siglo Veintiuno, 1978.

Revuelta González, Manuel, La exclaustración (1833-1840), Madrid, Biblioteca de Autores Cristianos, 1976.

Rodríguez Álvarez, Ramón, "El fondo histórico de las bibliotecas universitarias españolas. El fondo de la biblioteca de la Universidad de Oviedo", en El libro antiguo en las bibliotecas españolas, Oviedo, Universidad de Oviedo, Servicio de Publicaciones, 1998, pp. 111-135.

Rodríguez Álvarez, Ramón, La Biblioteca de la Universidad de Oviedo 1765-1934, Oviedo, Universidad de Oviedo, 1993.

Rubió i Balaguer, Jordi, "Organització de la biblioteca de la universitat", en Sobre biblioteques i biblioteconomia, Barcelona, Departament de Cultura de la Generalitat de Catalunya, Publications de l’Abadia de Montserrat, 1995.

Torres Rodríguez, Casimiro, "Las constituciones de la biblioteca universitaria de Santiago y su primer catálogo en el siglo XVIII", en Cuadernos de estudios gallegos, XX, núm. 60 (1965), pp. 109-119. 